\title{
UNA EXPERIENCIA DE CONCIENCIACIÓN FUNDAMENTADA EN LA CREACIÓN DE RECURSOS EDUCATIVOS ABIERTOS DESDE LA EDUCACIÓN VISUAL Y PLÁSTICA
}

Recepción: 16/02/2019 | Revisión: 06/03/2019 | Aceptación: 25/05/2019

\section{Júlia CASTELL VILLANUEVA}

Universitat de Barcelona

julia.castell@ub.edu

\begin{abstract}
Resumen: En esta primera década del siglo XXI, el impacto de las políticas en abierto y su repercusión en los sistemas educativos de todo el mundo se han convertido en un tema de interés gracias a los esfuerzos y el liderazgo de diversas organizaciones y proyectos que promueven el aprendizaje a través de contenidos abiertos. OER Commons, The Saylor Foundation, Wikieducator Europeana, Learning Resource Exchange (LRE), Procomún o Khan Academy son solo algunos ejemplos significativos actuales de esta tendencia. La educación en abierto debería estar más cerca que nunca de conseguir esa oportunidad estratégica que representa y que permitiría mejorar definitivamente la calidad de la educación. Pero parece que su implementación no acaba de generalizarse, como podemos comprobar en este contexto de Educación Superior. El presente artículo parte de la experiencia realizada en la Facultad de Educación de la Universidad de Barcelona entre el alumnado de la asignatura Imagen Digital y Aprendizaje (6 ECTS) de la mención de Educación Visual y Plástica para reflexionar sobre la creación de recursos educativos abiertos.
\end{abstract}

Palabras clave: contenido abierto; educación visual y plástica; imagen digital; Recursos Educativos Abiertos; TIC.

\section{AN AWARENESS-RAISING EXPERIENCE IN ARTS EDUCATION BASED ONTHE CREATION OF OPEN EDUCATIONAL RESOURCES}

\begin{abstract}
In this first decade of the 21st century, the impact of open policies and their effects on the education systems around the world has become a topic of interest thanks to the efforts and leadership of various organizations and projects promoting learning through open content. OER Commons, The Saylor Foundation, Wikieducator, Europeana, Learning Resource Exchange (LRE), Procomún or Khan Academy are just a few current significant examples of this trend. Open education should be closer than ever to achieving the strategic opportunity that it represents, and which would definitely improve the quality of education. But it seems that its implementation is not just generalized, as we can see in this context of higher education. This article is based on the experience carried out in the Faculty of Education of the University of Barcelona with the students of the subject Digital Image and Learning (6 ECTS) of the Arts Education speciality to reflect on this issue.
\end{abstract}

Keywords: open sources; Plastic and Visual Arts; digital image; Open Educational Resources; ICT.

\section{UNA EXPERIĖNCIA DE CONSCIENCIACIÓ FONAMENTADA EN LA CREACIÓ DE RECURSOS EDUCATIUS OBERTS DES DE L'EDUCACIÓ VISUAL I PLÀSTICA}

Resum: En aquesta primera dècada del segle XXI, limpacte de les politiques en obert $i$ la seva repercussió en els sistemes educatius d'arreu s'han convertit en un tema d'interès gràcies als esforços $i$ el lideratge de diverses organitzacions i projectes que promouen l'aprenentatge a través de continguts oberts. OER Commons, The Saylor Foundation, Wikieducator, Europeana, Learning Resource Exchange (LRE), Procomún o Khan Academy són només alguns dels exemples significatius actuals d'aquesta tendència. L'educació en obert hauria d’estar més a prop que mai d’aconseguir aquesta oportunitat estratègica que representa $i$ que permetria millorar definitivament la qualitat de leducació. Però sembla que la seva implementació no acaba de generalitzar-se, com podem comprovar en aquest context d'Educació Superior. Aquest article parteix de lexperiència realitzada a la Facultat d'Educació de la Universitat de Barcelona entre lalumnat de lassignatura Imatge Digital $i$ Aprenentatge (6 ECTS) de la menció d’Educació Visual i Plàstica per a reflexionar sobre la creació de recursos educatius oberts.

Paraules clau: contingut obert; educació visual i plàstica; imatge digital; Recursos Educatius Oberts; TIC. 


\section{Introducción}

El siglo XXI ha comportado cambios significativos para nuestra sociedad que han provocado una nueva forma de entender el mundo y, consecuentemente, una nueva forma de entender la educación. La educación actual parece configurarse como una educación a largo plazo que nos acompañará durante toda la vida y que nos permitirá ir adaptándonos a los constantes cambios que irán aconteciendo, contribuyendo así a generar un nuevo modelo de desarrollo social. La Organización de la Naciones Unidas para la Educación, la Ciencia y la Cultura, UNESCO, desde su posición como institución mundial observadora de estas transformaciones, parece orientarnos con su liderazgo hacia un debate de políticas públicas, instándolos a replantear la educación en términos de globalización y políticas abiertas. La UNESCO (2015a) ve en el acceso universal a una educación de calidad un elemento esencial para la construcción de la paz, el desarrollo sostenible de la sociedad y la economía, y el diálogo intercultural. En este nuevo contexto mundial de aprendizaje, se requieren nuevas prácticas y nuevos puntos de vista, y los «Recursos Educativos Abiertos» (REA) - en inglés Open Educational Resource (OER) - deberían configurarse como un elemento catalizador de esta transformación educativa (UNESCO, 2015b). Pero, a pesar de conformarse como una especie de potente «arma» por la que todos deberíamos apostar abiertamente, que debería cambiar el panorama educativo y, por ende, cambiar el mundo en las próximas décadas, parece que esta idea no acaba de penetrar con suficiente profundidad en el sistema educativo.

\section{Un poco de historia para contextualizar la importancia de los Recursos Educativos Abiertos (REA) / Open Educational Resources (OER)}

Aunque anteriormente se habían realizado otras experiencias y encuentros internacionales significativos ${ }^{1}$, no sería hasta el Forum on the Impact of Open Courseware for Higher Education in Developing Countries, celebrada en el año 2002, cuando se empezase a abordar más profundamente el tema de las políticas educativas abiertas. Fue precisamente en este foro donde surgió el término «Recurso Educativo Abierto» / «Open Educational Resource» —en adelante referenciado con la abreviatura REA/OER - definiéndolo como:

El suministro abierto de recursos educativos a través de tecnologías de la información y la comunicación, para ser consultados, empleados y adaptados por una comunidad de usuarios con fines no-comerciales (UNESCO, 2002:24)

Este término presentó en su origen, y sigue presentando aún ahora, cierta confusión, al encontrar otros términos homólogos para hacer referencia a lo que consideramos recursos

1 La Budapest Open Access Initiative en 2001, que pretendía acelerar el esfuerzo internacional para conseguir el acceso libre en internet (open access) a los artículos de investigación en todos los campos académicos. En 2003 se proclama también la Declaración de Berlín sobre Acceso Abierto al Conocimiento en Ciencias y Humanidades que advierte sobre la necesidad de sistemas de certificación de esta nueva manera de intercambio educativo. La que probablemente representa la primera gran acción significativa en materia educativa en abierto fue la OpenCourseWare, de la mano del Instituto Tecnológico de Massachusetts (MIT) que, con la publicación de contenidos docentes en abierto a través de la red, acabaría popularizando en poco tiempo los famosos MOOC (Massive Online Open Courses). 
educativos abiertos - como por ejemplo «recursos didácticos online», "materiales educativos en red», «materiales de aprendizaje abiertos», etc. - - Sin embargo, estos recursos, con mayores o menores matices, siempre deben ser considerados materiales cuyo acceso a través de la red es

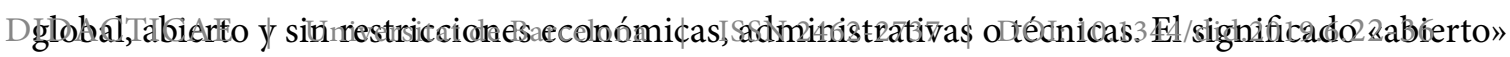
en relación a los materiales RAE/OER propone liberar cualquier limitación para convertirse en contenido libre totalmente abierto, es decir, en recursos de enseñanza, aprendizaje e investigación de dominio público o que han sido liberados bajo alguna de las diferentes licencias de propiedad intelectual que permiten su libre uso y reproducción por parte de terceros. Por ello, la definición inicial realizada por la UNESCO fue posteriormente matizada y ampliada haciendo referencia a los REA/OER como:

Cualquier recurso educativo (incluso mapas curriculares, materiales de curso, libros de estudio, streaming de videos, aplicaciones multimedia, podcasts y cualquier material que haya sido diseñado para la enseñanza y el aprendizaje) que esté plenamente disponible para ser usado por educadores y estudiantes, sin que haya necesidad de pagar regalías o derechos de licencia. (UNESCO, 2015b: 4)

Aunque quizá la definición más utilizada para definir a los REA/OER es la que se refiere a este tipo de materiales como:

Recursos de aprendizaje digitales que se ofrecen en línea (aunque a veces en forma impresa) libre y abiertamente a profesores, educadores, estudiantes y otros estudiantes independientes para que puedan ser utilizados, compartidos, combinados, adaptados y ampliados en un contexto de enseñanza, aprendizaje e investigación. Incluyen contenido de aprendizaje, herramientas de software para desarrollar, usar y distribuir, y recursos de implementación como licencias abiertas. El contenido de aprendizaje es material educativo de una amplia variedad, desde cursos completos hasta unidades más pequeñas como diagramas o preguntas de prueba. Puede incluir texto, imágenes, audio, video, simulaciones, juegos, portales, y similares (Hylén et al., 2012:18)

La Organización para la Cooperación y el Desarrollo Económico (OCDE), por su parte, define los recursos educativos abiertos como «materiales digitalizados ofrecidos libremente y abiertamente para profesores, alumnos y autodidactas a fin de que sean usados y reutilizados para enseñar, mientras se aprende y se investiga». Estos recursos digitales incluyen «contenidos educativos, el software de desarrollo, el uso y la distribución del contenido, y la implementación de recursos tales como las licencias abiertas» (OECD, 2009:14). Y en esta misma línea, la Declaración de Educación Abierta de Ciudad del Cabo, celebrada en el año 2007, añade a esta definición la idea de que la educación abierta no se limita solo a la utilización de recursos educativos abiertos, sino también a las tecnologías abiertas que facilitan un aprendizaje colaborativo, flexible y en el hecho de compartir prácticas de enseñanza.

Como podemos apreciar en estas definiciones, el concepto REA/OER va más allá de los propios materiales y amplía el término a todo tipo de recursos, incluyendo programas, recursos y técnicas. Por tanto, podemos decir que podemos encontrar recursos educativos abiertos en todo el espectro educativo, mutando y diversificando su forma de presentación para favorecer un mejor y más rápido desarrollo de una educación universal sin límites ni restricciones. Ya no se trata solo de contenidos, sino también de programas y de cualquier otro material o recurso tecnológico que permita o comporte un acceso libre a la educación. 
En noviembre de 2013, la fundación filantrópica americana William and Flora Hewlett Foundation, publicó un «libro blanco» (William and Flora Hewlett Foundation, 2013) que representa una hoja de ruta de referencia mundial para transformar la enseñanza y el aprendizaje a través de un movimiento a pequeña escala que afecte directamente la práctica de la educación en todos sus niveles. Esta fundación propone liberar cualquier limitación para convertir los recursos educativos en contenido abierto, permitiendo libertad total de uso y reproducción por parte de cualquier persona.

\subsection{Entrando en contexto: la problemática de la propiedad intelectual en la creación de Recursos Educativos Abiertos (REA/OER)}

Uno de los grandes problemas que condiciona el uso de materiales en abierto resulta precisamente el complejo mundo de los derechos de autoría de las imágenes que varía, además, en función del tipo de uso o la legislación del país en el que se aplique. Los REA/OER se presentaban como recursos educativos con una licencia que facilitaba su reutilización, y potencial adaptación, sin tener que solicitar autorización previa al titular de dichos derechos (UNESCO, 2015b). Por eso, más allá de los indiscutibles derechos morales de autoría - que son irrenunciables e inalienables y protegen la identidad y su reputación-, la aparición de las licencias abiertas generaron con su nacimiento un gran revuelo en el confuso marco legal de los derechos patrimoniales o de explotación relacionados con propiedad intelectual, los permisos y licencias (dominio público, derecho de divulgación, derecho de modificación, derechos de retirada, derecho a la integridad de la obra, etc.).

Un estudio promovido por COMMUNIA - una red europea de abogados y activistas en materia de propiedad intelectual en elámbito de la educación que reclama la reforma delos derechos de autoría en un contexto educativo- evidencia las enormes desigualdades en cuanto a la forma en que se puede acceder a los materiales y cómo utilizarlos para la enseñanza y el aprendizaje de calidad. Así, por ejemplo, en países como España, Francia o Dinamarca, no se puede reproducir libremente un vídeo de YouTube en clase, pero sí en Alemania o el Reino Unido (Nobre, 2017). Otro estudio europeo sobre la repercusión de la Directiva 2001/29/CE y los derechos de autor en la comunidad educativa (European Union, 2016) apunta que más del 60\% de los educadores y estudiantes encuestados, ante los obstáculos relacionados con derechos de autoría, evitan utilizar dichos materiales digitales por temor a las repercusiones legales. En España, las excepciones se consideraban demasiado complicadas para poder utilizarlos eficazmente con fines pedagógicos, por lo que los encuestados mayoritariamente se muestran a favor de un uso no autorizado aunque, en realidad, las cifras indican que experimentan menos obstáculos en comparación con la media europea.

Los recursos educativos deberían siempre ser compartidos a través de licencias que faciliten un uso y disipe cualquier duda sobre posibles restricciones de autoría, por lo que el uso de licencias abiertas sin duda se presenta como una buena iniciativa. Existen diferentes tipos de licencias, pero quizá la más conocida o visible actualmente sean las licencias Creative Commons 
que, para Labastida e Iglesias (2006), parecen haberse convertido en un estándar de facto en Internet. El proyecto Creative Commons en España se inició en febrero del año 2003, dos años después de su nacimiento en Estados Unidos, con la intención de ofrecer una manera simple y estandarizada de otorgar permiso al público para compartir y usar un trabajo creativo bajo términos y condiciones diversos. Es precisamente esta libertad de acceso su máximo atractivo, ya que no solo representa la posibilidad de hacer realidad el viejo sueño de una educación libre y de calidad para todas las personas, sino que también puede funcionar como un nuevo revulsivo en nuestro panorama educativo tecnificado e innovador. Las licencias abiertas facilitan el uso y distribución de los REA/OER, permitiendo a cualquier persona, en cualquier momento, reutilizar o revisar el material, dándole nueva vida al original, mejorándolo. Esta potencialidad responde a lo se conoce como el «modelo de las $\mathbf{4 R}$ » (Reutilizar- Revisar- Remezclar- Redistribuir) que fue revisado y modificado a su vez, años más tarde, añadiendo el derecho a hacer y poseer copias a este modelo para transformarlo así en el «modelo mejorado de las 5R» (Wiley, 2016).

\section{The 5R Permissions of OER}

\begin{tabular}{|c|c|}
\hline Retain & - Make and own copies \\
\hline Reuse & - Use in a wide range of ways \\
\hline Revise & - Adapt, modify, and improve \\
\hline Remix & - Combine two or more \\
\hline Redistribute & - Share with others \\
\hline
\end{tabular}

Figura 1. Categorización que conforma el modelo mejorado de las $4 R$ de Wiley. Fuente: Entrada en el blog de Wiley,12 de febrero de 2016.

Las recomendaciones recogidas en el «modelo mejorado de las 5R» están pensadas para alargar el ciclo de vida útil de los recursos educativos abiertos. Escoger un formato que facilite su uso y reedición permite que puedan producirse mejoras - tanto en su contenido como en su presentación - que hagan, por ejemplo, que el recurso pueda traducirse a otros idiomas, que pueda adaptarse mejor a otras plataformas tecnológicas o que se creen versiones alternativas con accesibilidad mejorada para llegar a conectar con el mayor número de personas posibles.

\subsection{Algunas iniciativas destacadas centradas en los Recursos Educativos Abiertos (REA/OER)}

Desde un punto de vista pedagógico, los REA/OER intentan proveer recursos de calidad que se adapten perfectamente al cambio educativo que se está produciendo en estas últimas décadas, que viene condicionado por un cambio de rol de cada representante del contexto educativo y en el que, un nuevo alumnado, más activo y creativo, parece ser el protagonista. Esta proactividad 
debería comportar un uso más rápido y personalizado de los materiales, pero para que este uso sea realmente efectivo y consiga llegar al máximo de personas, debe estar bien organizado y fácilmente localizable. De otra manera un retorno a la comunidad para continuar con un buen funcionamiento de la rueda educativa abierta resultaría mucho más lento y complejo. Es importante, por tanto, favorecer el uso de repositorios ya que, como apunta Wiley (2000), es la mejor manera de asegurar un buen acceso a este tipo de materiales. No obstante, existen también otras vías que facilitan la búsqueda y recuperación de recursos educativos abiertos - además de favorecer su preservación y aumentar la visibilidad - como pueden ser los portales temáticos, las comunidades virtuales, las revistas abiertas, las redes sociales, entre otros (D’Antoni, 2006).

En esta línea, destacamos algunas iniciativas importantes a tener en cuenta, creadas específicamente con la finalidad de permitir más fácilmente la localización de recursos educativos abiertos, más allá de otro tipo de iniciativas compilatorias de material educativo que permiten utilizar libremente materiales con finalidad educativa - pero que no necesariamente presentan una identificación de permisos licenciada específica- como el Banco de imágenes y sonidos del Ministerio de Educación, la red XTEC, Edumet, Educarm, Educastur, EducarEx, etc. En este punto debemos recordar que, aunque un recurso educativo no presente ningún tipo de licencia, no significa que pueda utilizarse libremente sin autorización, por lo que la utilización de repositorios y buscadores especializados en recursos abiertos resulta fundamental en este sentido para facilitar el acceso a materiales realmente abiertos.

En el año 2006, la Open University del Reino Unido junto a la William and Flora Hewlett Foundation, desarrolló un proyecto para establecer un repositorio abierto, el OpenLearn, que acabaría convirtiéndose en una comunidad internacional de investigación centrada en el impacto de los recursos educativos abiertos en las prácticas de enseñanza y aprendizaje. En este mismo año surge la comunidad WikiEducator, promovida por la Commonwealth of Learning, que actualmente difunde recursos educativos bajo un modelo de gobierno comunitario coordinado por el Open Community Council. El OER Commons (2007) surgió como biblioteca digital para facilitar el uso, evaluación y mejora de materiales REA/OER a través de un sistema inicial de etiquetaje y calificación con metadatos, que realizan docentes, estudiantes y personas expertas en la materia. Su lucha por conseguir estándares de calidad llevó a sus responsables a crear el Institute for the Study of Knowledge Management in Education (ISKME) para mejorar la práctica del uso de contenidos de aprendizaje de código abierto con una pedagogía basada en la investigación centrada en el aprendizaje participativo para docentes y estudiantes. La Open Education Consortium (OEC), una red mundial de instituciones y organizaciones comprometidas con la educación abierta y su impacto en la educación global e inclusiva, trabaja activamente en el desarrollo de políticas abiertas y de sensibilización, creando modelos de educación abierta sostenibles que permitan la colaboración e innovación internacional para conseguir el empoderamiento a través de la educación y diferentes iniciativas de concienciación y difusión como la Open Education Week, la Open Education Global conference, y los Open Education Awards for Excellence. El Learning Resource Exchange (LRE), un servicio creado por la European Schoolnet -fundado en 1997 para ayudar a las escuelas en su transformación tecnológica - funciona como una red de repositorios 
de contenido de aprendizaje apoyada por 34 países de la Comunidad Europea que permite intercambiar recursos de aprendizaje de alta calidad a docentes de diferentes países. La biblioteca en línea, OER Commons, creada en 2007 por el Institute for the Study of Knowledge Management in Education, permite el acceso a materiales educativos libres, facilitando el uso, evaluación y mejora de los recursos y la colaboración entre docentes. La CK-12 Foundation (2007) intenta conseguir un libre acceso a contenidos educativos de alta calidad y personalizables en múltiples modalidades en la educación secundaria obligatoria americana. El portal Open Education Europa (2013), que forma parte de la iniciativa Opening Up Education, reúne recursos educativos en distintos idiomas para facilitar su uso entre estudiantes, docentes y personal investigador. La Saylor Academy se dedica a crear cursos abiertos universitarios y profesionalizadores con certificación basados en una estructura libre que organiza, a través de la plataforma libre Moodle, utilizando materiales REA/OER que recopila y/o crea con licencias Creative Commons. La red social de colaboración para docentes Curriki fomenta la colaboración de experiencias abiertas en todo el mundo que son evaluadas en el aula y revisadas por pares para asegurar su eficacia. WikididacTICa, creada de forma colaborativa por docentes, presenta recursos digitales, experiencias y prácticas innovadoras, con contenido abierto educativo disponible bajo licencia Creative Commons. Khan Academy, una iniciativa personal de Salman Khan, que empezó a colgar vídeos en la plataforma Youtube y acabó convirtiéndose, gracias a la Fundación Bill y Melinda Gates, en una asociación sin ánimo de lucro a nivel mundial, produce contenidos educativos en forma de vídeos relacionados con el currículo escolar y distribuidos de forma totalmente gratuita.

Centrado en un contexto de Educación Superior, en 2011 aparece la Open Education Resource Universitas (OER $u$ ) una red mundial de instituciones educativas financiada por la UNESCO y la Fundación REA para facilitar el acceso a cursos gratuitos en línea para estudiantes de todo el mundo que intenta que los estudiantes que utilizan recursos educativos abiertos puedan

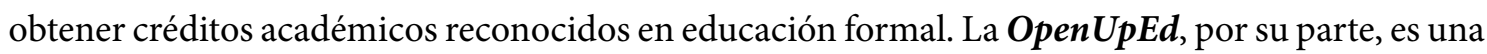
iniciativa MOOC lanzada en 2013 por iniciativa de la Comisión Europea en la que participan entre otras universidades la Universidad Nacional de Educación a Distancia (UNED)y la Universitat Oberta de Catalunya (UOC).

En territorio español, las universidades son las instituciones que presentan una mayor implicación en el desarrollo y apoyo de los repositorios como afirma Abadal (Abadal et al., 2013), especialmente gracias al trabajo realizado por los Centros de Recursos para el Aprendizaje y la Investigación (CRAI) conocido originariamente como Learning Resources Centres (LRCs), un servicio internacional de biblioteca presencial y digital que, además de ofrecer los servicios habituales que le son propios, dispone de centros de producción que permiten crear materiales docentes propios a la comunidad educativa, fomentando la apertura de materiales y recursos en abierto, accesibles, libres, inmediatos, gratuitos e innovadores.

Otras iniciativas destacadas en el ámbito educativo son: el Proyecto EDIA (Educativo, Digital, Interactivo y Abierto) del Centro Nacional de Desarrollo Curricular en Sistemas no Propietarios (CeDeC), creado en 2009 como organismo dependiente del Ministerio de Educación, Cultura y Deporte de España. Procomún (2014) es un espacio destinado a usos educativos y 
de aprendizaje dentro del cual encontramos un repositorio de recursos educativos en abierto clasificado de forma estandarizada (LOM-ES) para un uso directo El Instituto de Enseñanzas a Distancia de Andalucía (IEDA) también cuenta con un repositorio con cientos de materiales. Y el Portal Ceibal recoge igualmente recursos para Educación Primaria, Secundaria y Superior, tanto para el uso del alumnado como del propio docente.

Estos son solo algunos ejemplos de dónde podemos dirigirnos para buscar REA/OER, aunque podemos encontrar también contenidos educativos libres en otras iniciativas como Archive. org, la Biblioteca Digital Mundial de la UNESCO, el directorio internacional de repositorios en acceso abierto OpenDOAR, el portal Europeana, Hispana, etc.

\section{Una experiencia tangible en educación superior: el respeto de la autoría en la generación y producción de imágenes digitales para la creación de Recursos Educativos Abiertos (REA/OER)}

En la Facultad de Educación de la Universidad de Barcelona, realizamos una experiencia durante los cursos 2015-2016 y 2016-2017 con el alumnado de la asignatura obligatoria 363199 Imagen Digital y aprendizaje (6 ECTS) de la mención de Visual y Plástica del grado de Educación Primaria. El desarrollo de la experiencia, realizada durante toda la duración del curso, gira en torno a los objetivos de la asignatura, que se estructuran en base a conocimientos; habilidades y destrezas; y a las actitudes, valores y normas relacionadas con el uso del potencial de las tecnologías digitales en la educación visual y plástica. La asignatura, que está destinada principalmente a mejorar las competencias digitales de los futuros docentes, siempre desde un punto de vista creativo que aporta el tratamiento de la imagen digital, utiliza activamente recursos y herramienta libres para trabajar con la imagen digital; y profundiza en su implementación en un contexto educativo real al servicio del aprendizaje significativo. Al ser una asignatura de la mención de Visual y Plástica, se presta especial atención a dos elementos: el propio proceso creativo en relación a la gran carga visual que presentan los recursos educativos en la actualidad y la potencialidad de que dichos recursos puedan llegar a convertirse en recursos educativos abiertos. En el proceso creativo de producción de estos recursos no se olvida tampoco, como apunta Cruz (2011), que también resulta importante centrarse en las propias competencias digitales durante el proceso de producción de estos recursos educativos. Estas incluyen la utilización de ordenadores, el conocimiento de los programas, la ética sobre el plagio y una actitud positiva. En esta asignatura se trabaja, por tanto, en base a las siguientes competencias transversales:

- Identificación de necesidades informativas aprendiendo a refinar las búsquedas y analizando, procesando, valorando, usando y comunicando de manera eficaz, crítica y creativa.

- Fomento de un correcto uso de las nuevas tecnologías de la información y la comunicación para aprender, comunicarse y compartir conocimiento.

- Orientación en la planificación, organización y gestión de procesos, información, resolución de problemas y proyectos. Favoreciendo la iniciativa, el espíritu emprendedor y la capacidad de generar nuevas ideas y acciones. 
Además, se tienen en cuenta una serie de competencias específicas que acaban de precisar el marco de acción sobre el que se fundamenta el desarrollo de la asignatura:

- Diseño y desarrollo proyectos educativos, unidades de programación, entornos, actividades y materiales, incluidos los digitales, que permitan adaptar el currículum en la diversidad del alumnado y promover la calidad de los contextos en los cuales se desarrolla el proceso educativo, de forma que se garantice el bienestar.

- Integración de las tecnologías de la información y comunicación a las actividades de enseñanza y aprendizaje guiado y autónomo.

\subsection{Un estudio prospectivo sobre el conocimiento del alumnado en materia de políticas educativas abiertas}

Como paso introductorio al inicio de la asignatura, procedimos a realizar un sondeo prospectivo el primer día de curso en el que, entre otras preguntas relacionadas con la materia objeto de estudio de la asignatura, se hacía especial incidencia en diferentes cuestiones relacionadas con las tecnologías de la información y la comunicación (TIC), las tecnologías del aprendizaje y el conocimiento (TAC) y el uso y conocimiento directo e indirecto de diferentes recursos y materiales considerados «abiertos».

El objetivo general del sondeo era conocer el nivel de conocimiento de los Recursos Educativos en Abierto, específicamente relacionado con la competencia digital específica en el ámbito de los estudios de Magisterio que tiene el alumnado del último curso del Grado de Educación Infantil, justo antes de abandonar el ámbito universitario e incorporarse al mundo laboral.

El sondeo de tipo exploratorio, temporalmente transversal y cronológicamente prospectivo, utiliza un diseño no experimental capaz de mostrar la realidad sin intervención directa, permitiéndonos conocer y describir con mayor precisión un fenómeno concreto de tipo educativos en una circunstancia temporal determinada. El grupo muestra estaba formado por 70 personas, dividido en dos momentos temporales diferentes: el grupo-clase del curso 2015-2016 ( $\mathrm{n}=38$ alumnos) y el curso 2016-2017 ( $\mathrm{n}=32$ alumnos). Se utilizó el cuestionario como herramienta de recogida de datos, un instrumento creado ad-hoc para ser aplicado de forma manual en las mismas aulas en las que se impartía la docencia habitual de la asignatura. Los datos obtenidos, tratados anónimamente mediante códigos de identificación para preservar el anonimato del estudiantado, se procesaron posteriormente de forma cuantitativa a través del uso de categorías inducida y se realizó un análisis de dichos datos de manera estadística utilizando el programa libre de análisis predictivo GNU PSPP 1.0.1 (v.303). Los resultados estadísticos descriptivos de la muestra realizada ( $13 \%$ hombres, $87 \%$ mujeres) nos indican un leve porcentaje superior en el conocimiento de recursos REA/OER por parte de las mujeres (57,2\% hombres frente $60,4 \%$ mujeres). Esta diferencia no resulta especialmente significativa para diferenciar el resto de resultados por sexos; por tanto, las cifras se presentan en un concepto globalizador sin diferencias de género. 
La gran mayoría de los alumnos, en materia tecnológica, se consideran usuarios básicos en un 49,1\%. Un 43,6\% se consideran usuarios de tipo medio y tan solo un 7,3\% se consideran usuarios avanzados, tal y como se puede ver gráficamente a continuación: (Gráfico 1). Y en relación a los conocimientos sobre REA/OER, más de la mitad, es decir un $69,1 \%$ afirma no conocer las siglas ni saber a qué hacen referencia, un $20 \%$ conocen las siglas y afirman saber algo al respecto y el 10,9\% restante, además de conocer las siglas sabe explicar qué son los recursos educativos abiertos. (Gráfico 2)

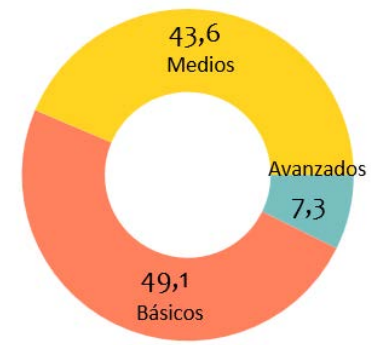

Gráfico 1. Porcentaje de autocategorización sobre conocimientos informáticos. Fuente: Elaboración propia.

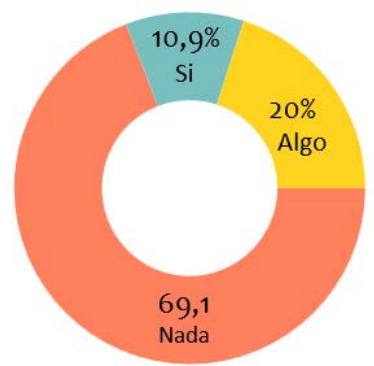

Gráfico 2. Porcentaje de nivel de conocimiento sobre Recursos Educativos Abiertos. Fuente: Elaboración propia.

Sorprendentemente, al preguntarles sobre sus hábitos cotidianos en el uso informático, hacen referencia en muchos casos a sistemas operativos y herramientas de software libre como Ubuntu, Firefox, Audacity, Gimp o Libre Office, sin ser conscientes de su carácter «libre»o «abierto». Este elevado porcentaje de desconocimiento en temas de educación abierta nos alerta sobre las negativas consecuencias de la inercia de lo cotidiano y, especialmente, sobre la falta reflexiva en los procesos educativos que comporta que la rueda de generación de nuevos materiales de acceso abierto se detenga, y con ella el impacto de las políticas educativas abiertas y el acceso universal al conocimiento. La deficiencia detectada resulta ciertamente sorprendente en Educación Superior ya que, por su próxima condición de docentes, deberían estar informados de las políticas educativas abiertas y de sus ventajas educativas para poder funcionar como faros replicantes de conocimiento. Pero como apunta Conole (2010), las nuevas propuestas pedagógicas y el uso innovador de las tecnologías parecen ofrecer muchas promesas, sin embargo, en realidad continúan existiendo pocas evidencias de que esté sucediendo de forma generalizada.

Un estudio de mayores dimensiones realizado en un periodo cronológico similar (20132015), enmarcado en el proyecto OER Research Hub y desarrollado por un equipo de investigación del Institute of Educational Technology de la Open University en el Reino Unido encabezado por De los Arcos et al. (2015), demostró que el uso de los REA/OER representa una oportunidad excepcional en educación formal al mejorar sustancialmente el nivel de satisfacción de los estudiantes ya que les permite obtener mejores resultados en las evaluaciones. La implementación y uso de los REA/OER pueden mejorar el rendimiento educativo de los alumnos, pero a menudo 
lo hacen de forma indirecta a través de un incremento de la confianza, satisfacción e interés de los estudiantes por el tema. Por su parte, los educadores que utilizan material abierto suelen manifestarse altamente satisfechos, y buscan y comparten asiduamente este tipo de materiales, convirtiéndose en defensores activos de su uso, haciendo que su uso crezca de forma constante y sostenida. Sin embargo, tan solo el $12,4 \%$ de los docentes crean recursos educativos publicados con licencias Creative Commons y, tanto para el profesorado como para el alumnado, continúan siendo desconocidos y escasamente utilizados de forma generalizada los repositorios REA/OER.

\subsection{La importancia imbricada del tratamiento de la imagen digital y el dominio de las TIC en un contexto abierto}

Los «nuevos medios de comunicación», desde el punto de vista de su técnica y de su manipulación, según apunta Deloche (2002), son portadores de un indiscutible potencial de transformación de lo real y obligan a abrir un nuevo debate: la manipulación de la imagen. Para este autor, el «ciberespacio» y el «cibermundo» no son más que productos de una nueva mutación que incrementa el poder del hombre sobre sí mismo y sobre las cosas. Para dominar estos medios propone desarrollar algunas estrategias basadas en el conocimiento y el control técnico de la imagen y de sus efectos, seleccionándolas y utilizando todo su potencial, construyendo una ética de las nuevas imágenes ya que esta es un mediador universal que actúa remitiéndose a lo sensible para poder dominar la civilización de las imágenes.

Es importante ser consciente de que se vivimos sometidos a un nuevo concepto visual. Dada la ausencia de poder y de autoridad, como apunta Kress (2005) se insiste en la enseñanza de principios de valoración, análisis y comparación, por lo que resulta esencial proporcionar medios basados en principios para valorar afirmaciones hechas sobre la verdad y la autoridad. Los procesos y ambientes de representación y la conciencia del diseño, tanto en su producción y articulación como en la interpretación resultan cruciales en este proceso.

La presencia de las TIC ha producido profundos cambios en el contexto educativo al revolucionar los métodos y técnicas creativas tradicionales, sometiéndolos a una constante mutación tecnológica imparable. Estos cambios, además de influir en la forma de enseñar con los medios, han proporcionado nuevas técnicas que permiten optimizar y flexibilizar la información y el acceso a esta. Sin duda, «el aprendizaje no se encuentra en función del medio» (Cabero, 2001:308), pero una buena interacción del medio, con los contenidos y materiales de información, con todos los participantes, sin duda lo propicia. La información que podemos encontrar en Internet es, como afirman Area y Ribeiro (2012:14), «abundante, multimedia, fragmentada y construida socialmente en entornos tecnológicos» por lo que se presenta necesaria una nueva alfabetización que nos capacite para actuar autónomamente, de forma crítica, al movernos en el medio digital. La alfabetización visual es uno de los raseros fundamentales de la educación ya que como afirma Dondis (1990:207) «debemos reflexionar, observar en profundidad lo que experimentamos, ver cómo otros logran sus propósitos y ensayarlos nosotros mismos». El tiempo de experimentación, la participación y el análisis de lo compartido es necesario para unir la intención con los resultados, 
tanto en el modo verbal como en el visual. Las imágenes, además de tener un significado por sí mismas, transmiten significado por su distribución en el espacio, tanto en relación a su ubicación precisa como en relación al diálogo que se establece con otros elementos próximos, ya sean visuales o textuales (Kress y van Leeuwen, 1996).

En la concepción de la asignatura la idea de generar conciencia sobre un uso y consumo respetuoso de recursos educativos aparece siempre latente y estrechamente imbricada al propio proceso artístico y al desarrollo competencial digital. Como afirma Richard Stallman, las actividades relacionadas con la educación (incluidas las escuelas de todos los niveles, desde preescolar hasta la universidad) tienen el deber moral de enseñar únicamente programas libres:

\begin{abstract}
Enseñar a los alumnos a utilizar software libre y a participar en la comunidad del software libre es una lección cívica llevada a la práctica. También les enseña que el modelo a imitar es el del servicio público y no el de los grandes magnates. Las escuelas de todos los niveles deben utilizar software libre (Stallman, 2003).
\end{abstract}

Durante el desarrollo de la asignatura se les va instando a utilizar programas libres, alternativos a los convencionales programas comerciales como podemos ver detallado a continuación:

- GIMP - GNU Image Manipulation Program: programa de edición de imágenes digitales en forma de mapa de bits, alternativa a la versión comercial Photoshop.

- INKSCAPE Draw Freely: programa de edición de vectores gráficos, alternativa a las versiones comerciales Adobe Illustrator o CorelDRAW.

- SCRIBUS Open Source Desktop Publishing: programa de autoedición para la creación de publicaciones, alternativa libre a las versiones comerciales Adobe PageMaker, QuarkXPress o Adobe InDesign.

Como futuros docentes, tan importante como el desarrollo artístico y el dominio de las herramientas tecnológicas es el conocimiento de los condicionantes que comporta el uso de las imágenes a la hora de utilizarlas como recursos educativos - ya sea de forma exenta o como parte de un material educativo más elaborado- y su repercusión. El acercamiento al tema se plantea de forma general despejando dudas iniciales con las que podían encontrarse en su día a día como docentes sobre el tema de la propiedad intelectual y los derechos de autor, sin entrar en complicados entresijos legales. Facilitando información sobre la identificación de licencias, se genera una dinámica que facilite su integración natural a la hora de plantear la creación de nuevos materiales, proponiendo la resolución de actividades —en primera instancia de tipo instrumental y posteriormente actividades más complejas y creativas-que ejemplifican diferentes requerimientos durante el curso en base a planteamientos reales con soluciones múltiples y diversos criterios estéticos y visuales.

El alumnado aprende a ir refinando sus métodos de búsqueda informativa a medida que avanza el curso, adecuándolos a las necesidades de cada momento, pero siempre bajo la filosofía de la educación libre: desde la búsqueda directa de imágenes filtrando por tipo de licencia a través 
del buscador por antonomasia Google hasta el uso de repositorios especializados como Morguefile, Pixabay, Open Clip Art Library, Wikimedia Commons, WikiArt Visual Art Encyclopedia, Web Gallery of Art o Europeana.

\section{Conclusiones}

La Declaración de Educación Abierta de Ciudad del Cabo (Open Society Foundations, 2007), defendía la idea de que todos los recursos educacionales financiados con los impuestos de los contribuyentes deberían ser recursos educativos abiertos. La Declaración de París (UNESCO, 2012) recogía esta idea al realizar un llamamiento a todos los gobiernos para licenciar abiertamente el material educativo financiado con fondos públicos. Como docentes formadores de futuros agentes educadores, debemos colaborar en la medida de nuestras posibilidades a este llamamiento, no solo por las ventajas y beneficios que comporta para todos los actores implicados, como hemos visto, sino también por las cuestiones éticas y morales que comporta el ser partícipes de un sistema educativo público. Adoptar prácticas educacionales, construidas en torno a la creación de nuevos REA/OER, pensados para compartir y construidos con herramientas no comerciales, promueve fácilmente la cooperación, fomenta la autonomía, potencia la creatividad y la imaginación y, en definitiva, nos prepara para capacitarnos como ciudadanos críticos, independientes y solidarios en la sociedad digital que vivimos.

La experiencia de aula desarrollada durante el transcurso la asignatura trataba de poner el foco de atención en los procesos de generación - haciendo consciente al alumnado de las implicaciones del uso de la información fluctuante en internet y, especialmente de las imágenes en relación a la autoría y propiedad - de contenidos educativos propios personalizados, de calidad y para compartir, ya que como apuntas Jenkins (2009) jóvenes productores al compartir evidencian prácticas de autonomía y soberanía sobre los contenidos.

El consumidor de la mayor parte de la producción de los medios educativos «no es capaz de detectar, por emplear una analogía con la alfabetización verbal, el equivalente a una falta de ortografía, a una frase incorrectamente formulada o a un tema mal estructurado» (Dondis, 1990:26). Por ello, en una sociedad eminentemente visual, en la que la imagen capitaliza nuestra atención, tenemos la obligación como docentes de «alfabetizar visualmente». La creación de estos materiales, diseñados con criterios de coherencia estética para un uso directo y concreto en el aula resulta, además, una buena manera de concienciar sobre la importancia de las políticas abiertas, favoreciendo un uso generalizado de materiales REA/OER, con el objetivo de sumar esfuerzos en la mejora de las políticas educativas abiertas, haciendo crecer una comunidad educativa comprometida. 


\section{Referencias bibliográficas}

Abadal, E., Ollé Castellà, C., Abad-García, F., y Melero, R. (2013). Políticas de acceso abierto a la ciencia en las universidades españolas. Revista Española de Documentación Científica, 36(2), e007. doi: http://dx.doi.org/10.3989/redc.2013.2.933

Area, M., y Ribeiro, M. T. (2012). De lo sólido a lo líquido: las nuevas alfabetizaciones ante los cambios culturales de la Web 2.0. Comunicar, 38, 13-20. doi: http://dx.doi.org/10.3916/ C38-2012-02-01

Cabero, J. (Ed.). (2001). Tecnología educativa: Diseño y utilización de medios en la enseñanza. Barcelona: Paidós.

Conole, G. (2010). Learning design - making practice explicit. En ConnectEd Design Conference, 28 de junio - 2 de julio 2010. Sydney, Australia. Recuperado de http://oro.open. ac.uk/22890/2/Conole.pdf

Cruz, V. (2011). Competencia para el diseño y producción de recursos digitales [objetos de aprendizaje]. Recuperado de http://catedra.ruv.itesm.mx/handle/987654321/368

Deloche, B. (2002). El museo virtual. Hacia una ética de la nueva imagen. Gijón: Trea.

Dondis, D.A. (1990). La sintaxis de la imagen. Introducción al alfabeto visual. Barcelona: Gustavo Gili.

D’Antoni, S. (2006). The virtual university. Models and messages. lessonsfrom case studies. Paris: Unesco Publishing. Recuperado de: https://unesdoc.unesco.org/ark:/48223/pf0000146558

De los Arcos, B., Farrow, R., Perryman, L.-A., Pitt, R., Weller, M., y McAndrew, P. (2015). OER research hub data 2013-2015. Building understanding of Open Education. OER research hub. Recuperado de https://oerknowledgecloud.org/sites/oerknowledgecloud.org/ files/20151117-OER-Hub-Data-Report.pdf

European Union (2016). Assessment of the impact of the European copyright framework on digitally supported education and training practices. Directorate-General for Education, Youth, Sport and Culture (European Commission). Luxemburg: Publication Office of the European Union. doi: 10.2766/453732 Recuperado de https://publications.europa.eu/en/ publication-detail/-/publication/1ba3488e-1d01-4055-b49c-fdb35f3babc8

Hylén, J., van Damme. D., Mulder, F., y D’Antoni, S. (2012). Open Educational Resources: Analysis of responses to the OECD Country Questionnaire. OECD Education Working Papers, 76. Paris: OECD Publishing. doi: http://dx.doi.org/10.1787/5k990rjhvtlv-en

Jenkins, H. (2009) Fans, blogueros y videojuegos. La cultura de la colaboración. Barcelona: Paidós comunicación.

Kress, G., y van Leeuwen, T. (1996). Reading images: The grammar of visual design. Londres: Routledge.

Kress, G. (2005). El alfabetismo en la era de los nuevos medios de comunicación. Málaga: Aljibe.

Labastida, I., e Iglesias, C. (2006). Guía sobre gestión de derechos de autor y acceso abierto en bibliotecas, servicios de documentación y archivos. SEDIC. Recuperado de http://hdl.handle.net/2445/32170 
Nobre, T. (2017). Copyright and education in Europe: 15 everyday cases in 15 countries. Final report COMMUNIA. International Association of the Digital Public Domain. Recuperado de https://www.communia-association.org/wp-content/uploads/2017/05/15casesin 15 co untries FinalReport.pdf

OECD (2009). El conocimiento libre y los recursos educativos abiertos. Mérida: Junta de Extremadura. doi: https://doi.org/10.1787/9788469180822-es.

Open Society Foundations (2007). Declaración de Ciudad del Cabo para la Educación Abierta: Abriendo la promesa de Recursos Educativos Abiertos. Recuperado de https://www.capetowndeclaration.org/read-the-declaration

Stallman, R. (2003). Why schools should exclusively use free software. GNU operating system. Recuperado de https://www.gnu.org/education/edu-schools.es.html

UNESCO (2002). Forum on the impact of open courseware for Higher Education in developing countries. Paris, 1-3 julio. Recuperado de https://unesdoc.unesco.org/ark:/48223/ pf0000128515

UNESCO (2012). Declaración de París sobre los REA. Congreso mundial sobre los Recursos Educativos Abiertos (REA). Recuperado de http://www.unesco.org/new/fileadmin/MULTIMEDIA/HQ/CI/CI/pdf/Events/Spanish Paris OER Declaration.pdf

UNESCO (2015a). Replantear la educación. ¿Hacia un bien común mundial? Recuperado de http://unesdoc.unesco.org/images/0023/002326/232697s.pdf

UNESCO (2015b). Guía básica de Recursos Educativos Abiertos (REA). Recuperado de http:// unesdoc.unesco.org/images/0023/002329/232986s.pdf

Wiley, D. (2000). Connecting learning objects to instructional design theory: a definition, a metaphor, and a taxonomy. En D. Wiley (Ed.) The instructional use of learning objects: online version. Recuperado de http://reusability.org/read

Wiley, D. (12 de febrero de 2016). Slow or sophisticated? Squandered or sustainable? [Entrada en un blog]. Recuperado de https://opencontent.org/blog/archives/4443

William and Flora Hewlett Foundation (2013). White paper: Open Educational Resources. Breaking the lockbox on education. Recuperado de https://hewlett.org/library/white-paper-openeducational-resources/ 